\title{
Controlling Risks in ICT investments with Real Options thinking
}

\author{
Georgios N. Angelou, Anastastios A. Economides \\ University of Macedonia \\ gangelou@tee.gr, economid@uom.gr
}

\begin{abstract}
Organizations are making large investments in information communication technology (ICT). However, many are risky and are often considered runaway, because they do not meet original expectations of cost, time, or benefits. Effective management of risks in ICT projects is therefore extremely important. In this paper we propose real options (ROs) thinking for controlling risks in ICT projects. We present a framework for understanding and hedging risks in ICT projects based on the finance literature on ROs. However, existing RO models are based on quantitative analysis and the required input parameters sometimes may be difficult to be estimated for evaluating real life investment opportunities. Instead we adopt a qualitative options thinking for finding the optimum deployment strategy for an ICT project. The proposed framework is applied to a real life ICT case study showing how it can be formulated and solved.
\end{abstract}

Keywords: Real Options, Controlling ICT risks, Decision Analysis, Information Communication Technologies, Investments analysis.

\section{Introduction}

Organizations are making large investments in information communication technology (ICT) and there is growing realization that ICT investments can be a significant source of competitive advantage (Kumar, 2002). ICT projects are often difficult to estimate and manage and some projects are canceled or reduced in scope because of overruns in cost and/or time or failure to produce anticipated benefits. Hence, effective management of ICT project risks is a challenging task in many organizations. The purpose of this article is to propose a framework for managing risks in ICT projects. This framework is based on research in finance on real options theory. The proposed framework represents a systematic approach to risk management in ICT projects. There is empirical evidence to support the fact that managers who are aware of some options-like ideas do a better job of managing risky research and development (R\&D) projects (Kumar, 2002). Also, senior finance executives are becoming increasingly aware of the need to view major risky capital investments as options. ROs analysis for risk management in ICT investments has 
been applied by Benaroch (2002) and Kumar (2002). However, ROs models are based on quantitative analysis and the required input parameters sometimes are difficult to be estimated for evaluating real life investment opportunities. Such parameter is the revenue or cost uncertainty (volatility) for the investment opportunity. In addition, ICT investments experience tangible and intangible factors and the latter can be mainly treated by qualitative analysis (Gunasekaran et. al. , 2001). For this reason, we integrate ROs thinking and Analytic Hierarchy Process (AHP) to take into account financial tangible, intangible and risk factors providing a decision analysis framework. The proposed framework provides a better understanding of projects risks and various intangible factors inherent in ICT projects enabling these projects to be deployed more optimum and valued with higher accuracy.

The rest of the paper is organized as follows. In Section 2, we discuss the ICT risks; we present a background material on ROs and how they can be used for risk control. In Section 3 we discuss limitations of current ROs models and provide the reasons for qualitative options thinking and introduce AHP. In Section 4, we present the proposed methodology. In Section 5, we apply the proposed decision analysis framework to a real life case study. Finally, in Section 6, we conclude and suggest possible future research.

\section{Risk Management in ICT investments with Real Options}

Risk management strategies are oriented towards identifying different types of risks, assessing their relative importance for the project, and implementing strategies for managing risks (Kumar, 2002). ICT risks can be placed into three categories (Benaroch, 2002; Bräutigam and Esche, 2003). Firm-specific risks are due to uncertain endogenous factors (endogenous or technical uncertainty). They could be the result of uncertainty about the ability of the firm to fully fund a long-term capitalintensive investment, the adequacy of the firm's development capabilities to a target investment, etc. Competition risks are the result of uncertainty about whether a competitor will make a preemptive move, or simply copy the investment and improve on it. Market risks are due to uncertain exogenous factors that affect every firm considering the same investment (exogenous or market-related uncertainty). These risks could be the result of uncertainty about customer demand and prices for the products or services a target investment yields, potential regulatory changes, unproven capabilities of a target technology, and so on.

\section{ROs background material}

An option gives its holder the right, but not the obligation, to buy (call option) or sell (put option) an underlying asset in the future. Financial options are options on financial assets. Real Options (ROs) approach is the extension of the options concept 
to real assets. An investment project embeds a $\mathrm{RO}$ when it offers to the management the opportunity to take some future action (such as abandoning, deferring or expanding the project) in response to events occurring within the firm and its business environment (Trigeorgis, 1996). ICT research on real options recognizes that ICT investments can embed various types of ROs, including: defer, stage, explore, alter operating scale, abandon, lease, outsource, and growth. Trigeorgis (1996) provides an in-depth review and examples on different real options. For more practical issues the reader is referred to Mun (2002). Angelou and Economides (2004) present an extended survey of real options applications in real life ICT investment analysis. Each type of RO essentially enables the deployment of specific responses to threats and/or enhancement steps, under one of four investment modes (Benaroch, 2002).

Defer investment to learn about risk in the investment. If we don't know how serious some risk is, the option to defer investment permits learning about the risk by acquiring information passively (observe competitor moves, review emerging ICTs, monitor regulatory actions, etc.) or actively (conduct market surveys, lobby for regulatory changes, etc.).

Partial investment with active risk exploration in the building stage. If we don't know how serious some risk is, investing on a smaller scale permits to actively explore it. Three options facilitate learning-by-doing, that is, enable gathering information about the firm's technological and organizational ability to realize the investment successfully.

Full investment with reduction of the expected monetary impact of risk in the building and operation stages. Here, options help to lower the value consequences of risk and/or the probability of its occurrence. An example of the former is the option to lease development resources, which protects against development and market risks by allowing to kill an investment in midstream and save the residual cost of investment resources. A way to lower the probability of risk occurrence is the option to outsource development or operation. This option lowers the risk of development or operation failure by subcontracting (part or all of project) to a third party that has the necessary development capabilities and experience.

Dis-investment/Re-investment with risk avoidance in the operation stage. If we accept the fact that some risk cannot be actively controlled, two options offer contingency plans for the case it will occur. The option to abandon operations allows redirecting resources if competition, market or organizational risks materialize. The option to alter scale allows contracting (partially disinvest) or expanding (reinvest) the operational investment in response to unfolding market and organizational uncertainties. Based on the logic of these investment modes, the mapping of specific risks to specific options that control them can be refined to fit any class of ICT investments. 


\section{Real options limitations and AHP for qualitative analysis}

Several conceptual and practical issues emerge when trying to use in business practice options theory as proposed in the current ICT literature. So far in the literature, the ROs models concern quantitative factors analysis for both benefits and costs. However, very often an ICT project owns a number of qualitative factors that should be taken into account in parallel with the quantitative ones. In addition, the estimation of revenues and cost volatility, used as input parameters in the typical options values, can be a very difficult task. Benaroch (2002) provides a method for estimating the overall investment uncertainty (volatility), which it can be broken down into its components (e.g. customer demand uncertainty, competition uncertainty, technology uncertainty). However, the estimation of each component of the uncertainty may be impossible. We extent this thinking by considering that some of the overall uncertainty's components may be treated as qualitative factors, while the sources of uncertainty that can be quantified and included in the estimation of the overall project volatility can be integrated in the typical ROs models.

An important barrier to the successful implementation is a general inability to reliably estimate cash flows that are enabled by infrastructure investment. Existing models for option valuation assume a certain distribution of the resulting cash flows, based on an efficient market or another appropriate indicator of expected returns. However, this is only rarely the case in the context of investments in ICT business filed, which is known for its uncertain, and unpredictable business conditions. It has been further recognized that finance-oriented option valuation models are too complex for managerial decision-making practice. Options theory in its present state, does provide a conceptual decision framework to evaluate the prons and cons of an investment but in many cases it cannot be considered as a fully operation tool for management (Renkema, 1999). Hence, in many cases it is much more feasible, simpler and faster to apply what could be called "option thinking" in the context of risk control that an option can provide for a specific investment opportunity. This means that alternative options can be designed, categorized, and examined for finding the optimum combination of them that management intuition will recognize as the most promising in terms of risk mitigation. We enhance ROs analysis by adopting qualitative analysis for estimating the risk control between the various deployment alternatives for an investment, which may contain a number of ROs. We introduce the AHP methodology and construct a specific decision analysis model. To our knowledge this is the first time that the ROs and AHP are integrated into a common decision analysis framework.

AHP is a multi-criteria decision analysis technique. It aims at choosing from a number of alternatives based on how well these alternatives rate against a chosen set of qualitative as well as quantitative criteria (Saaty and Vargas, 1994; Schniederjans, 2005). By AHP it is possible to structure the decision problem into a hierarchy that 
reflects the values, goals, objectives, and desires of the decision-makers. Thus, AHP fits the strategic investments problems and the framework of this study. Concerning, examples of AHP application in ICT literature, Bodin et. al. (2005) proposed the AHP method to determine the optimal allocation of a budget for maintaining and enhancing the security of an organization's information system. Hallikainen et al. (2002) proposed an AHP-based framework for the evaluation of strategic IT investments. They applied the principles of AHP to compare a number of Information Technology investment alternatives. Tam and Tummala (2001) formulated and applied an AHPbased model for selecting a vendor for a telecommunications system. Lai et al. (1999) applied the AHP to the selection of a multimedia authoring system. Finally, Kim (1998) used the AHP to measure the relative importance of Intranet functions for a virtual organization.

\section{The proposed model-methodology}

Next, we present a methodology that helps to address the question: How can we control firm, market and competition risks so as to configure a specific ICT business activity in a way to minimize risk and increase investment performance? The proposed model contains three perspectives, financial tangible factors (FTF) perspective, risk mitigation (RM) perspective, and intangible factors (IF) perspective, Figure 1.

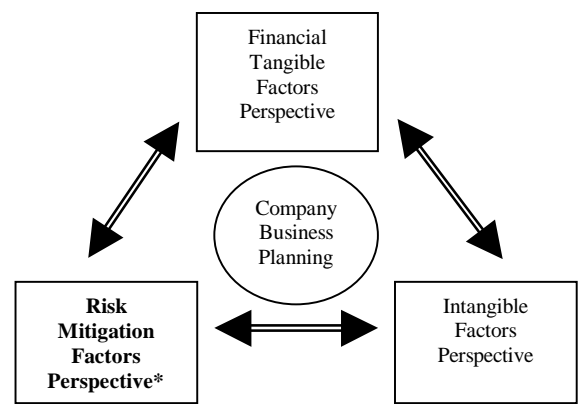

Figure 1. The proposed model - three perspectives

(*analyzed in this work)

In this work we focus on Risk Mitigation factors, while it is subject of further work to integrate FTFs and IFs perspectives in our analysis. However, we provide a brief introduction of these perspectives.

Financial Tangible Factors Perspective

The financial perspective evaluates how a company is meeting though financial measures. For the valuation of financial perspective we may adopt traditional accounting techniques such as Net Present Value (NPV), Return on Investment (ROI) 
and Internal Rate of Return (IRR). FTF for an investment opportunity mainly refers to the efficiency deriving from substituting the labor by the ICT. Within this dimension, the ICT value is associated with internal process automation and derived primary from productivity improvement, labor savings and operation cost reductions.

\section{Intangible Factors perspective}

Intangible factors are difficult, if not impossible, to quantify in absolute monetary terms, but are still important to the decision making process. Quantitative models cannot analyze these factors. Intangible factors can be separated in the following categories.

Information Effects that are related to the ICT ability to collect, store, process and disseminate information. Business value associated with information accrues from improved decision quality and employee empowerment. Transformation Effects that are related to the ICT ability to facilitate process innovation and transformation such as total quality management and business process reengineering. The business value associated with transformation will be manifested as improved responsiveness to the customer needs, and product or service enhancement as a result of redesigned organizational structures. Strategic-Long Term effects, which are_born by the initial project and its predefined options and cannot be clearly quantified. In particular, beyond the operational benefits that company is going to have from earlier phases projects, there are certain long-term strategic goals that can be achieved (e.g. the entrance of more value added advanced telecommunication services). In ROs literature investment opportunities, known in advance, based on initial infrastructure projects are treated as growth options, while for the estimation of their values compound option models are utilized. However, growth investment opportunities in reality can be hardly defined during decision phase (Benaroch, 2002). For this reason, we model qualitatively the existence of growth investment opportunities, which are based on projects in previous phases of a company's business activity and cannot be defined quantitatively in advance.

Risk Mitigation Factors Perspective

As mentioned before real options analysis can control different sources of risks existing in the various stages of the investment life-cycle. We use a classification for analytical definition of ICT risks based on Benaroch (2002) and (Bräutigam and Esche 2003) proposals. Table 1 shows the main sources of ICT risks as well as their mapping to the specific ROs that can control them. 
Table 1. Risk factors inherent in ICT investments and options that can control them

\begin{tabular}{|c|c|c|c|c|c|c|c|c|c|}
\hline \multirow[t]{2}{*}{ Risk Opportunity } & \multirow{2}{*}{\begin{tabular}{|c|}
$\begin{array}{c}\text { Recognit } \\
\text { ion }\end{array}$ \\
Defer \\
\end{tabular}} & \multicolumn{4}{|c|}{ Building } & \multicolumn{4}{|c|}{ Operation } \\
\hline & & Stage & \begin{tabular}{|c|} 
Explore/ \\
Pilot
\end{tabular} & $\begin{array}{c}\text { Outsource } \\
\text { Development }\end{array}$ & Lease & Abandon & Contract & $\begin{array}{c}\text { Expan } \\
\text { d }\end{array}$ & Outsource \\
\hline $\begin{array}{l}\text { F1 firm cannot afford the project (unacceptable } \\
\text { financial exposure) }\end{array}$ & + & & + & + & + & & & & \\
\hline $\begin{array}{l}\text { F2 costs may not remain in line with projected } \\
\text { benefits }\end{array}$ & + & & + & + & + & + & + & & + \\
\hline P1 staff lacks needed technical skills & + & + & + & + & + & & & & \\
\hline P2 project is too large or too complex & & + & + & + & + & & & & \\
\hline P3 inadequate infrastructure for implementation & & + & + & & & + & + & & \\
\hline P4 the project is not on Time & & + & + & & + & + & & & \\
\hline $\begin{array}{l}\text { F1 wrong design (eg, analysis failed to assess correct } \\
\text { requirements) }\end{array}$ & & + & + & + & & + & & & \\
\hline $\begin{array}{l}\text { F2 problematic requirements (stability, } \\
\text { completeness, etc.) }\end{array}$ & & + & + & & & + & & & \\
\hline O1 uncooperative internal parties & + & + & + & & & + & & & \\
\hline $\mathbf{O 2}$ parties slow to adopt the application & & + & + & & & + & + & & \\
\hline $\begin{array}{l}\text { C1 competition's response eliminates the firm's } \\
\text { advantage }\end{array}$ & + & + & + & & + & + & + & & \\
\hline C2 competition acts before the firm & + & & + & & & & & & \\
\hline $\begin{array}{l}\text { ETlow customer demand, with inability to pull out } \\
\text { of market }\end{array}$ & + & + & + & + & + & + & + & & + \\
\hline $\begin{array}{l}\text { E2 demand exceeds expectations (follow-up } \\
\text { opportunities exist) }\end{array}$ & + & & + & & & & & + & \\
\hline $\begin{array}{l}\text { E3 too high customer response may overwhelm the } \\
\text { application }\end{array}$ & + & & + & & + & + & + & + & + \\
\hline $\begin{array}{l}\text { E4 customers may (bypass) develop their own } \\
\text { solutions }\end{array}$ & + & & + & & & + & + & & \\
\hline E5 unanticipated action of regulatory bodies & + & & & & + & + & & & \\
\hline E6 Price uncertainty & + & & & & & + & & & \\
\hline $\begin{array}{l}\text { E7 environment changed requirements (expected } \\
\text { benefits vanish) }\end{array}$ & + & & + & & & + & & & \\
\hline $\begin{array}{l}\text { E8 Other factors such as Legal Issues, Natural } \\
\text { Phenomena, Social issues, Armed conflicts, } \\
\text { Taxation. }\end{array}$ & + & & & & & + & & & \\
\hline $\begin{array}{l}\text { T1 application may be infeasible with the } \\
\text { technologies considered }\end{array}$ & & + & + & + & + & + & & & + \\
\hline $\begin{array}{l}\text { T2 the introduction of a new superior } \\
\text { implementation technology may render the } \\
\text { application obsolete }\end{array}$ & + & & & & + & + & & & + \\
\hline $\begin{array}{l}\text { T3 the implementation technologies considered may } \\
\text { be immature }\end{array}$ & + & & + & + & & + & & & \\
\hline
\end{tabular}

\subsection{Integrating qualitative Real Options with AHP model}

The structure of the decision analysis framework contains four levels: i. the content of the specific investment opportunity which it can be deployed in various ways, ii. the adopted investment modes, iii. options level that embedded in each of the investment mode, iv. multi-criteria factors level that contains financial tangible, risk and intangible analysis, Figure 2. The overall utility of AHP structure is composed by these factors, which they may by further decomposed into their applicable sub-criteria 
and are closely related to the ROs and the investment issues coming from this analysis. We apply the pair-wise comparisons for each of these sub-criteria. The final result of the analysis, at the top, is the prioritization of the ICT deployment scenarios according to the overall utility factor.

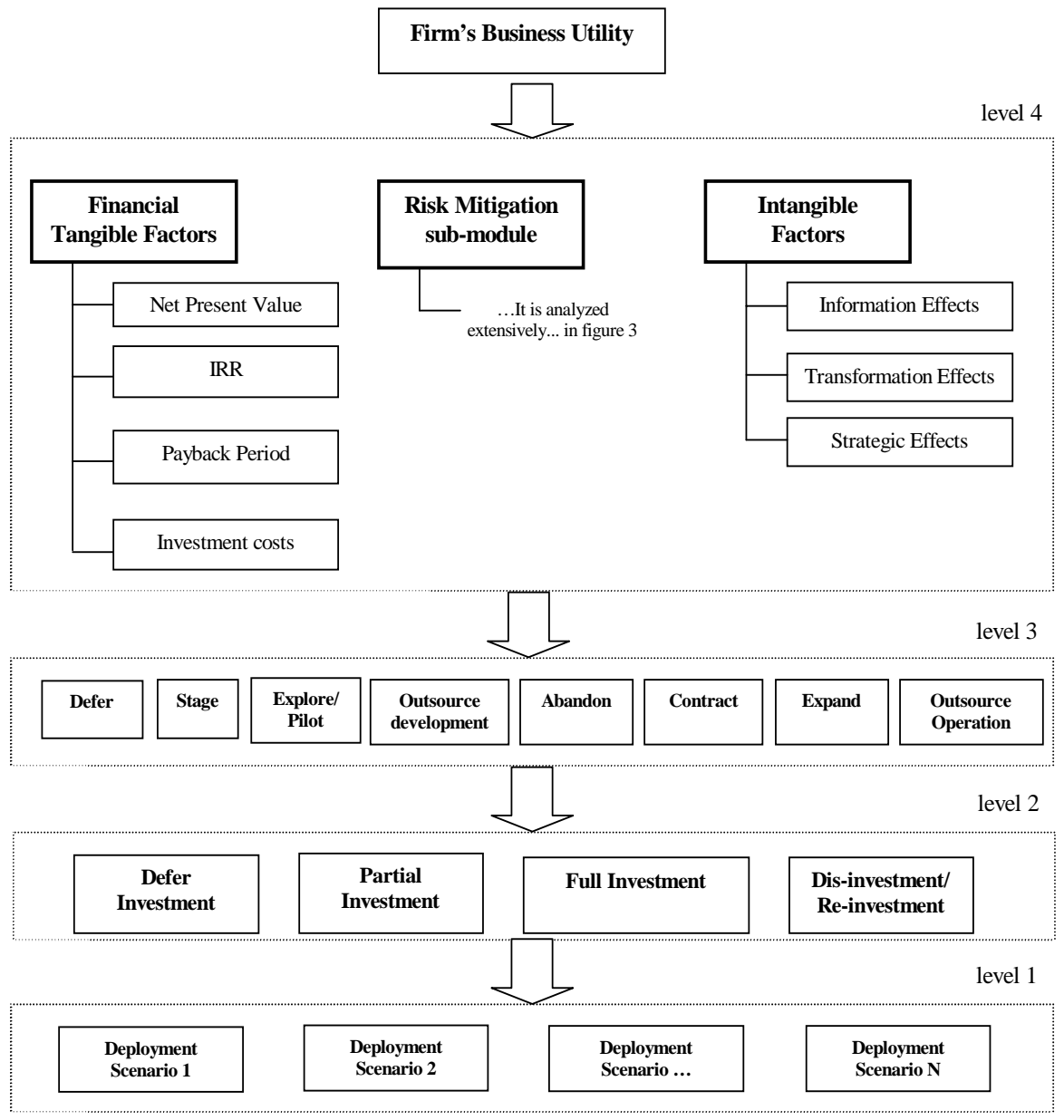

Figure 2. Analytical view of the decision analysis framework

The analytical view of the Risk Mitigation sub-module, which is analyzed deeply in this work is presented in Figure 3. The criteria used in our structure are coming from Table 1 and indicate the risk inherent in ICT investments. Analytically, we perform pair-wise comparisons of the deployment scenarios for each of the risk factors focusing on the risk control that each scenario can provide. The pair-wise comparisons concern the amount of risk that is resolved and controlled, depending on 
the option(s) adoption in each scenario. Our target is to select the deployment scenario that provides the highest value for the risk mitigation utility.

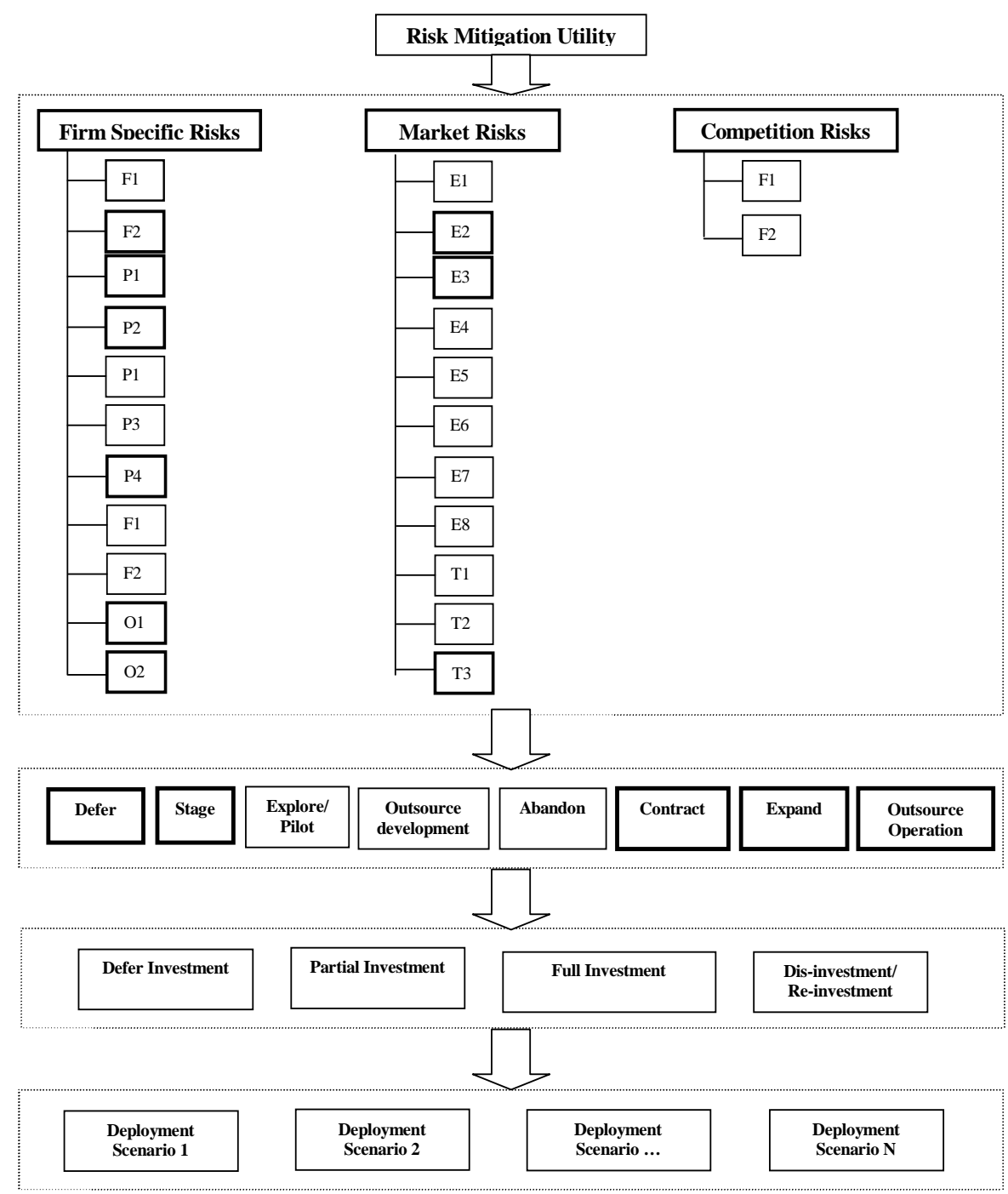

Figure 3. The risk mitigation sub-module of the proposed framework (risks relevant to the ICT investment of the case illustration are indicated by bold boxes) 


\section{$\underline{\text { Summary }}$}

Our methodology concerning risk mitigation utility maximization involves four main steps that must be repeated over time. These steps help to optimally configure and investment under the information set available, but as time passes they must be reapplied in case that some risks get resolved or new risks surface. In the following we present these steps.

- Define the content of the overall ICT business activity and its risk profile. State the investment goals, requirements and assumptions (technological, organizational, economic, etc.), and then identify the risks inherent in the investment.

- Recognize the options mapped to specific risks and use them to adopt investment modes to be examined.

- Evaluate investment-structuring alternatives (deployment scenarios) and find a subset of the recognized options that maximally contributes to the investment value.

- Perform sensitivity analysis in order to understand the contribution of each risk factor control in the overall risk control utility.

\section{A case illustration}

To illustrate the proposed methodology we apply it to an ICT investment decision for a growing Water Supply \& Sewerage Company, which we refer to as WSSC to protect its identity and its projects. The Company's principal business is the supply of water and sewerage services to over 1.5 million people. WSSC is interested in proceeding on implementation of a ICT platform in order to improve automation aspects of its operations, decision taken methods, customer services as well as new strategic opportunities in long-term perspective. Analytically, the investment opportunity under examination includes.

- Telemetry-ICT (TICT) infrastructure to enable WSSC to perform more efficiently water network management as well as Asset Management (AM).

- ArcInfo, a Geographical Information System (GIS), that allows users to create, view, access and analyze map (geo-referenced) data (GIS).

- StruMap, a Hydraulic Analysis simulation tool, which helps the Water Network Modeling and therefore the Water Management (HM).

- A web-based customers support tool (WB).

Of course, the whole system integration with the functional internal processes of the company requires re-engineering of the company's internal processes and especially these related to the customer support and information. Concerning the specific 
investment opportunity for the WSSC there are some risks that can influence negatively its performance. There are mainly company-specific, environmental and technological risks since the WSSC does not experience any customers demand uncertainty or any competition threat. ICT platform may experience lack of users acceptance, but also lack of WSSC technical expertise. Also, risk factors may concern unrealistic implementation schedule and environmental complexities such as installation of complex equipment in a large scale that can cause inconvenience to the customers. Risks modeling included in our analysis is given in gray cells in Table 1 . Finally, there is uncertainty about the firm's capability to integrate efficiently the initially planned scale of the ICT infrastructure with the required applications as well as with the content of them.

The overall investment deployment strategy in its most complex strategy can include all the options that can control partially or fully the specific investment's risks, Figure 4. In our analysis we consider the options to defer, stage, expand, contract and outsource operations. The investment's deployment scenarios to be examined are given below, Figure 5. We are looking for the optimum ranking of these scenarios.

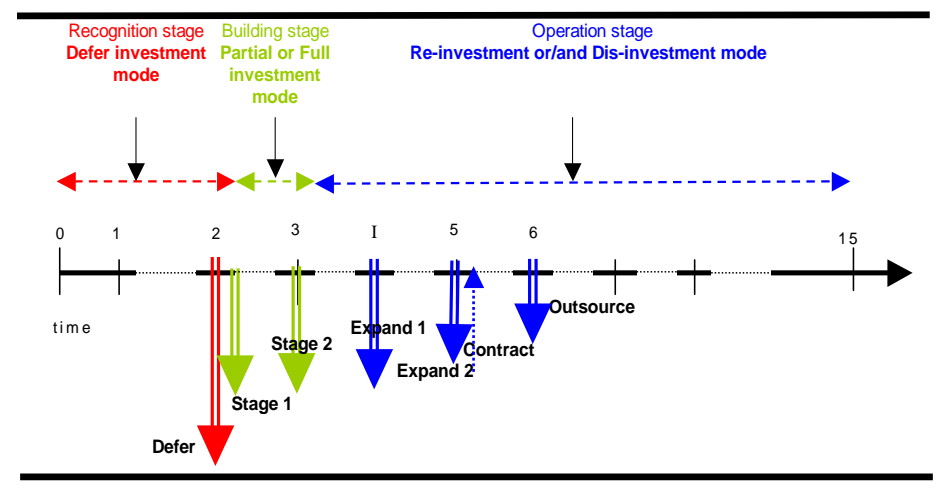

Figure 4. A configuration of options taken into account in our analysis

Defer: To defer (up to $\mathrm{T}_{\mathrm{d}}=2$ years) the base scale TICT - Stage: To build ICTP base scale platform in two stages at $\mathrm{T}_{\mathrm{s} 1}=\mathrm{T}_{\mathrm{d}}$ and $\mathrm{T}_{\mathrm{s} 2}=\mathrm{T}_{\mathrm{d}}+1$ option to stage 1 (S1) and option to stage 2 (S2) - Expand: To option to expand (E1) operation up to $\mathrm{T}_{\mathrm{e} 1}=\mathrm{T}_{\mathrm{d}}+2$ as well as the option to expand (E2) up to $\mathrm{T}_{\mathrm{e} 2}=\mathrm{T}_{\mathrm{d}}+3$ - Contract: The company's management may also decide to contract operation for investment stage (E1) instead of expanding them to (E2) if business conditions become unfavorable - Outsource: The company's management examines the possibility of outsourcing the base scale operation and maintenance of the T-ICT system up to 4 years of operation (i.e. at $\mathrm{T}_{0}=\mathrm{T}_{\mathrm{d}}+4$ ). The lyfe-cycle of the investment is 15 years. 
For the evaluation of the investment alternatives we do not adopt the quantitative analysis and existing ROs models such as Black-Scholes formula or binomial model. Our intentions was also supported by the interview process with the company's management, which revealed the degree of uncertainty for the various phases of the investment. The company's management expressed the uncertainties level for each investment phase in qualitative way, since it had difficulties in expressing the volatility of the expected value of investments benefits.

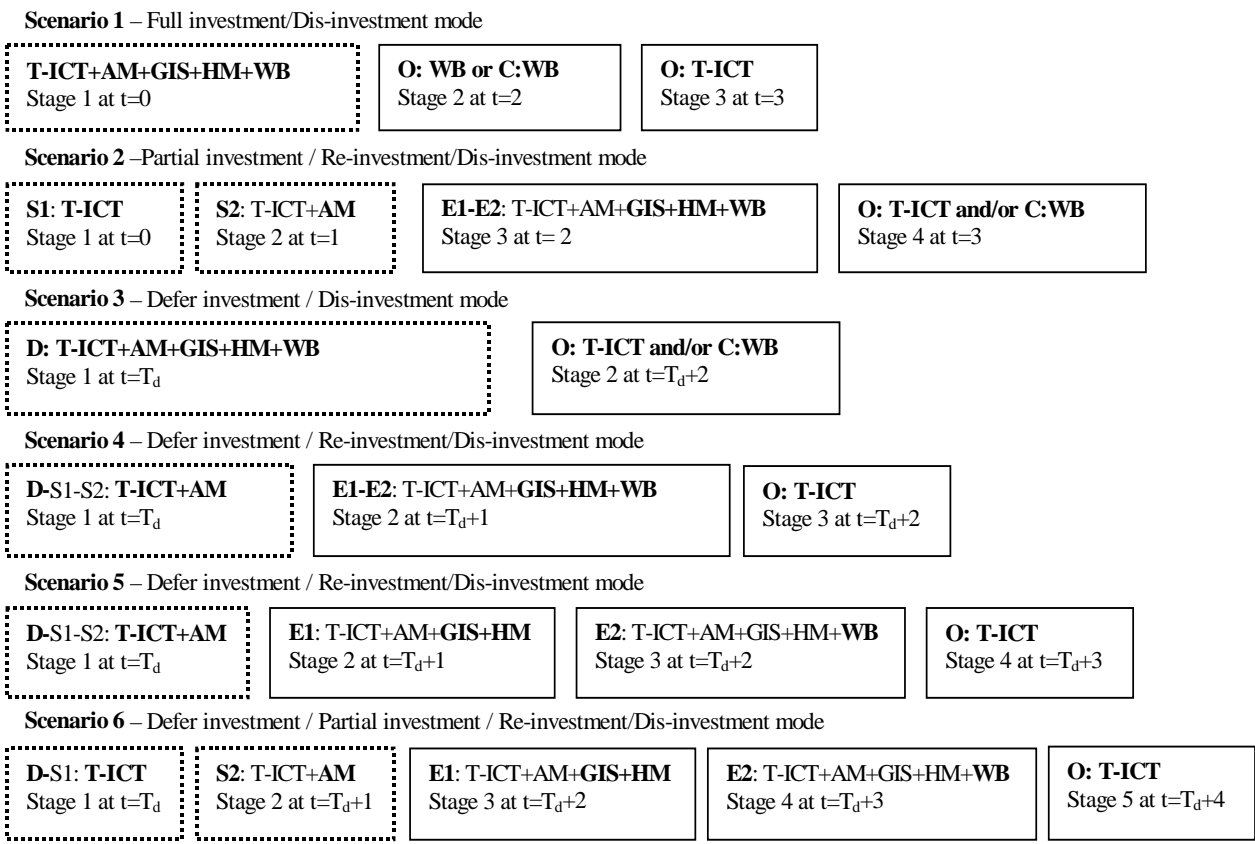

Figure 5. Scenarios examined (options combinations - investment content) The different boxes indicate different investment stages ( --- recognition and building stages, - operation stages )

Applying the proposed AHP methodology, the pair wise comparison matrices are derived and the relative performance measures are computed for intangible risk factors. We use the nine-point scale as suggested by Saaty et. el. (1994) however, modified in order to incorporate with our analysis. In particular, we judge our scenarios as extreme risk control (E), very strong risk control (VS), strong risk control $(\mathrm{S})$, moderate risk control $(\mathrm{M})$ and equal risk control (E) including intermediate values between the main characterization types. By using the Expert Choice and making judgments according the aforementioned nine-point scale we derive the pair wise comparison matrixes. In our analysis we achieve as consistency ratio level lower 
that 0.10 in order to be acceptable (Saaty, 1994). The prioritization results are given below, Figure 5.

Qerall Inoconsistency $=, 06$

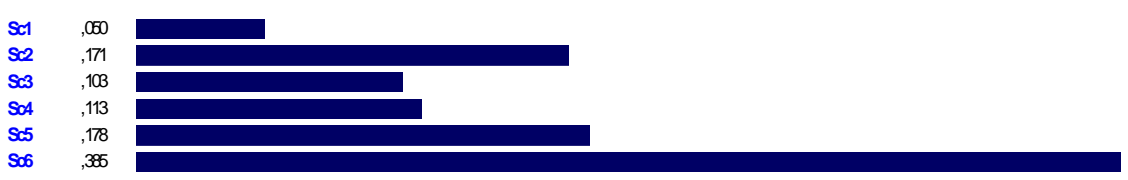

Figure 5. Scenarios prioritization performed with Expert Choice tool

As it can be seen higher risk mitigation utility value is given by scenario 6 and scenario 5 is following. However, though more option may generate higher control risks in general the financial tangible and intangible factors contribution may change the above conclusion.

Performing sensitivity analysis we can study how sensitive the priorities of the alternatives are to the changes of the input data, i.e. the importance of the criteria. Figure 6 shows the sensitivity analysis of the results with respect to the importance of firm risk factors.

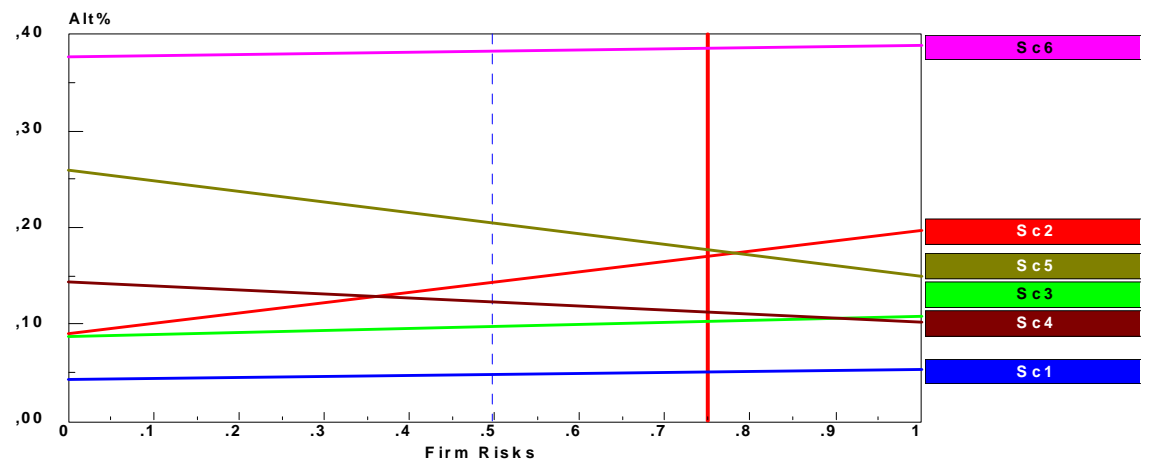

Figure 6. Sensitivity analysis for firm specific risks

The figure shows that scenario 6 experiences the highest utility value. Also, for firm risk factors weights from 0 up to 0,75 scenario 5 presents the second priority, while from 0,75 to 1 scenario 2 becomes the second best. The input data are quite subjective, especially the intangible ones. For this reason, it is important to study the dynamics of the sensitivities carefully. For example, if the importance of one-criterion changes significantly, the priorities of between scenarios may change due to space limitations we do not present these results while they are available to the interest reader. 


\section{Conclusion and future research}

In this work we provide a decision analysis framework for prioritizing ICT investment deployment strategies adopting qualitative option thinking. Analytically, we integrate ROs and AHP in a common multi-criteria decision analysis framework. The estimation of financial tangible and intangible factors for each of the deployment scenarios and their introduction in the overall utility function of the proposed AHP structure can make the analysis more complete and efficient.

\section{References}

Angelou G. and Economides A., 2005. Flexible ICT investements analysis using real options. International Journal of Technology, Policy and Management, 5(2):146166.

Benaroch M., 2002. Managing information technology investment risk: a real options perspective. Journal of Management Information Systems, 19(2): 43-84.

Bodin L., Gordon L. and Loeb M., 2005. Evaluating information security investments using the analytic hierarchy process. Communications of the ACM, 48(2):78 - 83

Bräutigam, J., Esche, C. 2003. Uncertainty as a key value driver of real options. 7th Annual Real Options Conference.

Expert Choice, 1995. Expert Choice for windows based on Analytic Hierarchy Process, Version 9, User Manual, Pittsburgh, PA.

Hallikainen P., Kivijarvi H. and Nurmimaki K., 2002. Evaluating strategic IT investments: An assesment of investment alternatives for a web content management system. Proceedings of the 35th Hawaii International Conference on Systems Sciences.

Gunasekaran A., Love E., Rahimi F. and Miele R., 2001. A model for investment justification in information technology projects. International Journal of Information Management, 21: 349-364.

Kim J., 1998. Hierachical structure of intranet functions and their relative importance: Using the analytic hierarchy process for virtual organizations. Decision Support Systems, 23:59-74.

Kumar R., 2002. Managing risks in IT projects: an options perspective. Information \& Management 40: 63-74.

Lai S., Trueblood P. and Wong K., 1999. Software Selection: a case study of the application of the analytic hierarchy process to the selection of multimedia authoring system. Information \& Management, 36: 221-232.

Mun J., 2002. Real Options Analysis: Tools and techniques for valuing strategic investments and decisions, Wiley Finance.

Renkema, T., (1999) The IT value quest: how to capture the business value of ITbased infrastructure, Jhon Wiley \& Sons, Ltd. 
Saaty T.L and Vargas L.G., 1994. Decision making in economic, political, social, and technological environments with the analytic hierarchy process. Pittsburgh: RWS Publications.

Schniederjans M., Hamaker J. and Schniederjans A, 2005. Information technology investment - decision-making methodology. Singapore: World Scientific Publishing.

Tam M. and Tummala R., 2001. An application of the AHP in vendor selection of a telecommunications system. Omega, 29: 171-182.

Trigeorgis L., (1996), Real options: managerial flexibility and strategy in resource allocation. The MIT Press. Cambridge MA. 